\title{
IDEAS \& An ecologically based landscape classification INNOVATIONS system for monitoring and assessment of pastures
}

\author{
Sarah Goslee, Matt Sanderson, Kenneth Spaeth, Jeffrey Herrick, and Kevin Ogles
}

T he pastures and haylands of the United States have substantial potential to contribute to national goals for sustainably increasing food production (Nelson 2012). Realizing this potential will require technologies and management strategies that are tailored to the agroecosystems of the region, are economically viable, enhance the environment, and are sufficiently flexible to adapt to climate change. Forage production is the foundation for pasture-based dairy and livestock production, including low input and organic systems, and contributes to confined animal feeding operations through hay production. Pastures often include a diverse mixture of numerous forage species, the identities of which depend on complex interactions between soil, climate, landscape, and management (Goslee and Sanderson 2010). Plant species composition affects not only plant productivity and length of grazing season, but also animal intake, production, and greenhouse gas emissions. An applied understanding of these complex relationships is lacking in current pasture classifications, even though an ecologically based framework is needed to support management practices that sustain biological integrity and enhance plant and animal productivity while minimizing adverse environmental impacts (Sanderson et al. 2011).

Effective ecosystem management requires that we simplify the complex natural world enough that we can understand how to manage it while at the same time not losing information necessary for meeting management objectives. Classification

Sarah Goslee is an ecologist at the USDA Agricultural Research Service Pasture Systems and Watershed Management Research Unit, University Park, Pennsylvania. Matt Sanderson is research leader at the USDA Agricultural Research Service Great Plains Research Laboratory, Mandan, North Dakota. Kenneth Spaeth is a rangeland management specialist at the USDA Natural Resources Conservation Service Central National Technology Support Center, Ft. Worth, Texas. Jeffrey Herrick is a research soil scientist at the USDA Agricultural Research Service Jornada Experimental Range, Las Cruces, New Mexico. Kevin Ogles is a grazing lands specialist at the USDA Natural Resources Conservation Service East National Technology Support Center, Greensboro, North Carolina. systems of various sorts, which may be based on plant species composition, soil physical and chemical properties, climate zones, and landscape position, are widely used for such applications (Mora and Iverson 2002; Rocchini and Ricotta 2007). It is impractical to treat each unit of land or each possible combination of climate, soils, and topography as an individual entity. Instead, we must group them into classes that have similar soils and climate, support similar vegetation, and respond similarly to management. At the same time, effective management requires acknowledgment that members of a class are not homogeneous so that recommendations may be tailored to a specific location. Conversely, any two classes are not necessarily equally different: information about one class may be relevant elsewhere, thus speeding development of management recommendations (see example below).

Topo-climatic classification is a wellestablished methodology, but most such classifications have focused on natural areas and conservation planning rather than agricultural systems (Burrough et al. 2001; Serra et al. 2011). Because of the complex drivers and dynamic ongoing nature of land use change on pastureland throughout the United States, a grazing landscape grouping system must describe potential use or probability of use, rather than solely current land use. Linking classification based on ecological processes with state and transition models offers a way forward.

\section{ECOLOGICAL FRAMEWORK}

In agricultural plant communities, component species can be planted or can enter from the regional species pool. Most pastures contain a mix of the two. In either case, site characteristics act to filter the species pool: particular combinations of soils, climate, and topography preferentially encourage some species over others. Tolerances to heat, freezing, drought, grazing, and other factors determine which forage species can be grown successfully at a particular site. Responses to environmental factors may be nonlinear, and there may be trade-offs between tolerances to different factors. For instance, species attri- butes conferring resistance to drought may also reduce freeze tolerance.

The behavior of species along single environmental gradients is fairly straightforward, but patterns are not so clear when applied to a real landscape with complex spatial patterns of multiple interacting factors. Underlying gradients are not usually smooth and continuous; there can be abrupt changes in soil type, underlying bedrock, topography, and so on that can result in corresponding discontinuities in plant communities. There can be distinct plant communities, and there can also be areas where species composition changes slowly across the landscape without any identifiable transitions from one community type to the next. In agricultural systems, management can enhance or obscure the response of plant species to environmental gradients. Management drivers, such as grazing, mowing, fertilizer application, and irrigation, add an additional level of filtering on top of the environmental constraints.

\section{EXPERIENCE FROM RANGELAND}

The use of ecological site descriptions (ESDs) for land use classification in rangelands is well-established and based on scientific principles (USDA NRCS 2003), but we lack a similar quantitative method for use in more humid grazed landscapes. Classification of these landscapes is further complicated by historic land cover and use, which often includes intermingled agriculture, development, and forest.

Early rangeland management was based firmly in the Clementsian successional concept, with management only able to speed or slow the inexorable progress toward the climax vegetation. This limited understanding was replaced by the state and transition concept, which recognizes that a site may support a number of similar plant communities (phases) within a single state, but that an irreversible threshold event may force that site into a different state (Westoby et al. 1989).Vegetation may move from one phase to another reversibly within a state, perhaps driven by short-term weather or management, but a shift from one state to another 
may not be easily reversible. An extreme example might be if virtually all of the soil organic matter were lost due to historic crop production practices. The original vegetation is highly unlikely to return within a management timeframe, and there are no cost-effective solutions for restoring that site.

Application of the state and transition concept is accompanied by delineation of ESDs based on soils, climate, and native vegetation (Bestelmeyer et al. 2003; Herrick et al. 2006). For each ecological site, a state and transition model is developed describing the potential plant communities and their drivers, as well as possible transitions between states. The rangeland ESD is based on the characteristic soils, hydrology, and historic plant community on nondegraded land. In areas where the historic native vegetation persists and is important for agricultural management, this is highly effective, but in many of the regions of the United States used for pasture, the native vegetation (e.g., forest over much of the eastern United States) does not figure into local agriculture. Instead, the concern is for plant communities containing largely naturalized species and maintained by management. Furthermore, due to historic land use (especially for cultivated agriculture), little undegraded land remains for most soil/climate combinations in more humid regions of the United States and much of the rest of the world.

\section{CURRENT STATUS OF PASTURE CLASSIFICATION}

Quantitative classification and monitoring tools are required in pastures, for both local management and national assessments of land condition, such as the pastureland component of the National Resource Inventory. Developing a more ecologically based site classification system is a core objective of the pastureland Conservation Effects Assessment Project (Sanderson et al. 2011). The current system of Forage Suitability Groups (FSGs) is organized around soil types and nested within Major Land Resource Areas (MLRAs). A single FSG consists of one or more soil map unit components having similar potentials and limitations for forage production (USDA NRCS 2003). The soils within a group support the same forage plants, have similar productivity, and require similar manage- ment. The creation of FSGs is based on soil survey units and relies on expert opinion for forage species, production, and management information. Such a qualitative system is extremely useful in areas where experts are available, but can be slow to develop, may be difficult to extend to new regions, and is lacking in a clear scientific framework. Any new system should depend on quantitative data and be grounded in ecological processes, relying on expert opinion to provide management recommendations within a solid classification framework.

To implement an ecologically based framework for pastures, several components are needed:

1. A quantitative classification methodology of sites types based on soil, climate, and topography that do or could support productive plant communities containing predominately forage species.

2. A classification of pasture plant community types and nonpasture endpoints (e.g., old field after abandonment or bare ground after severe disturbance).

3. For each site type, a listing of possible communities and their potential production for the range of variability of weather at that site.

4. For each site type, a description of management drivers that can maintain desirable states or force shifts from one community type to another, including irreversible thresholds that make land unsuitable for pasture.

Elements 1 and 2 adapt the rangeland ESD to a region where native climax vegetation is not a useful indicator of site type, and elements 3 and 4 together implement the state and transition model concept. This framework also supports the development of ecologically based monitoring and assessment tools that relate current pasture condition to the desired and achievable state given the site.

\section{CLASSIFICATION APPROACH}

We propose a three-step procedure for developing a landscape classification system relevant to pasture management and general agricultural uses that incorporates both ecological processes and expert knowledge of agricultural management responses.

1. Select topographic, climatic, and soil variables that are known to constrain potential plant community composition and plant production and that are widely available. The topographic and climatic variables will focus on descriptors of energy and water because those are the physical properties that determine plant community composition and production potential of a site, such as incident solar radiation, topographic curvature, and slope. Mean annual temperature, total precipitation, and temperature and precipitation during the growing season will be used to describe climate (see National Range and Pasture Handbook, Chapter 3, for lists of potentially important variables [USDA NRCS 2003]). Relevant soil properties, including texture, depth, available water holding capacity, and parent material, will be obtained from the new national Gridded Soil Survey Geographic (gSSURGO) database. Ordination will be used to reduce correlation among variables and eliminate overfitting (Mora and Iverson 2002; Serra et al. 2011). The same set of variables will also be used in forage production models and in models of forage species distribution, thus ensuring a common ecological framework.

2. Create a hierarchical classification using the selected variables and map both the discrete classification and the membership probability for each map pixel. Divisive hierarchical clustering methods will be used for site classification. For management purposes, a hierarchical classification is most suitable because it enables consideration of progressively finer-grained data. The most common sort of classification system is termed "crisp" because each pixel belongs to a single group. A "fuzzy" classification approach is a more sophisticated alternative; instead of each pixel assigned to a single class, the membership probability for each possible class is calculated. Each pixel thus has a set of membership probabilities rather than a binary group membership variable (Burrough et al. 2001; Serra et al. 2011). This probability can be turned into a crisp classification by assigning each pixel to the class with which it has maximum similarity. A fuzzy classification system allows more flexible management interpretations. The forage production models and species distribu- 


\section{Figure 1}

Environmental and land use information for Centre County, Pennsylvania: (a) elevation (30 m [98 ft] digital elevation model from US Geological Survey; solid line shows the boundary between Major Land Resource Areas 127 and 147), (b) land use classification (Fry 2011), and (c) mean annual temperature and (d) total annual precipitation (NACSE 2013).

(a)

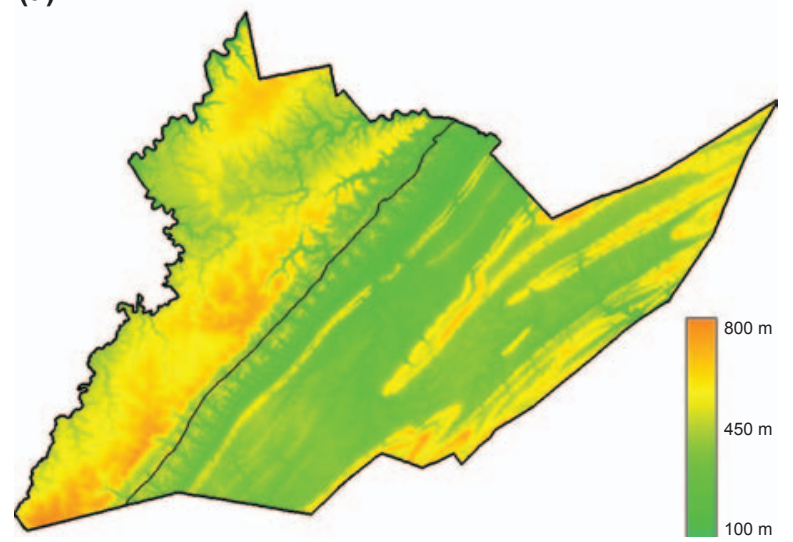

(c)

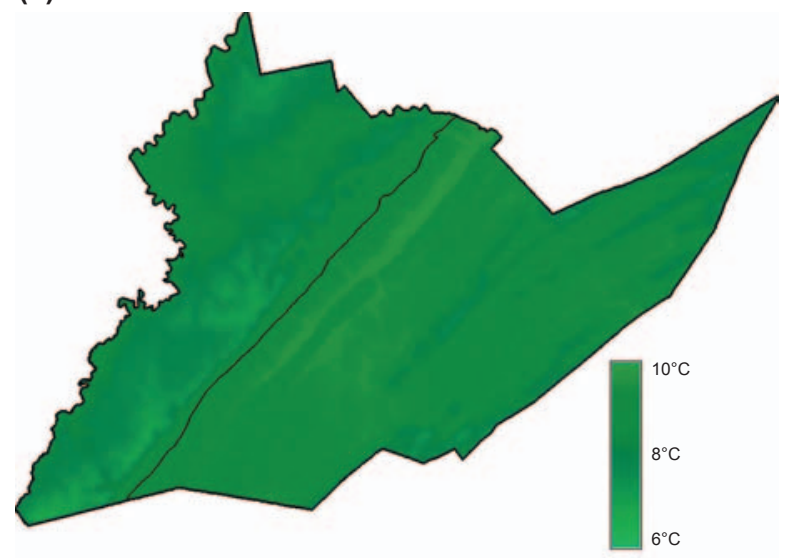

(b)

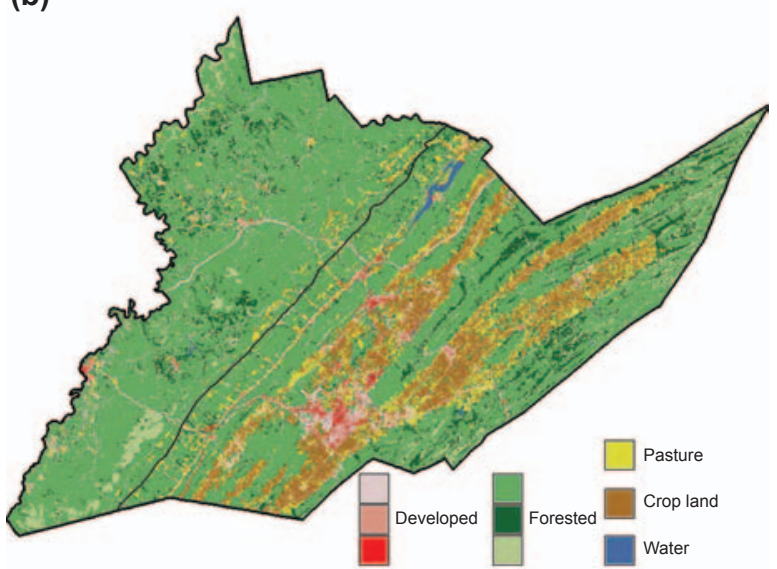

(d)

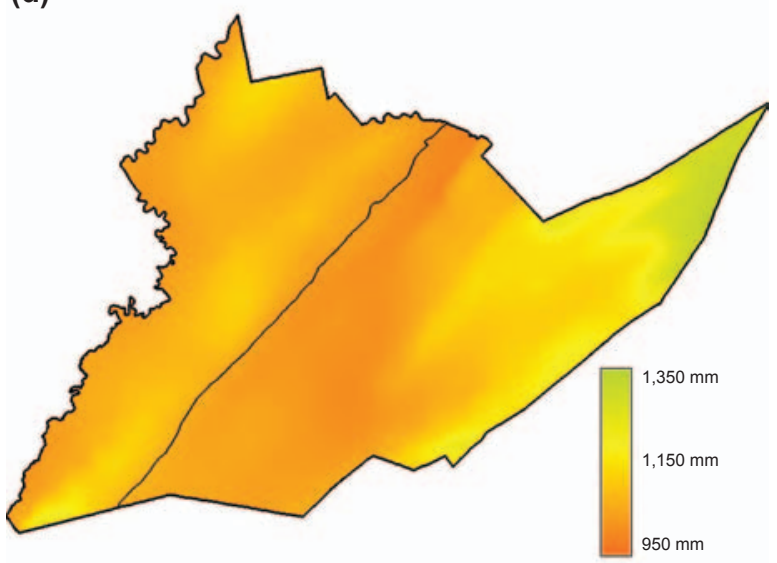

tion models based on the same variable set will then be applied to each class.

3. Solicit expert opinion from Natural Resources Conservation Service, Extension, and others to refine class descriptions and develop management recommendations tailored to each site class. The current FSG development framework incorporates management options that can only be obtained from those familiar with local grazing management. Such information is crucial to creating an agriculturally relevant classification. While species distribution and plant production models will be used to define baseline pasture potentials, modelbased information will be refined by consulting with experts in each region, particularly to characterize known variability within and between classes. Expert opinion on management practices appropriate for each site type and for the effects of those management practices on forage species production is also needed.

\section{PROBABILISTIC LANDSCAPE CLASSIFICATION}

We demonstrate our proposed probabilistic (fuzzy) landscape classification methodology using Centre County, Pennsylvania (figure 1). In 2006, this county was predominately forested (76\%), with $8 \%$ developed, $7 \%$ pasture, and 9\% crop (Fry et al. 2011) (figure 1b). Agriculture and development largely follow the valleys in the southeastern half of the county, leaving the ridges and northwestern highlands forested (figure 2). The northwestern highlands fall into the Eastern Allegheny Plateau and Mountains MLRA (127), and the southeastern area falls into the Northern Appalachian Ridges and Valleys MLRA (147).

This county-level demonstration was part of a preliminary project investigating scaling and statistical problems and included only topography and climate: elevation, slope, terrain curvature, incident solar radiation on June 20 and December 20, mean annual temperature, and precipitation. This variable set was taken from a series of tests of clustering methods; a more sophisticated set of variables that includes soil information to adequately represent agricultural potential will be used in the final landscape classification. All variables were scaled against the minimum and maximum values for the entire state of Pennsylvania.

A divisive hierarchical classification was used: the county was divided into two parts based on the included variables, then each of those was divided into two parts, and so on. Only the first level of classification (a single split into two groups) is shown here. The crisp classification (figure 3a) clearly divides the county into ridge and valley areas (compare to figure 1a). 


\section{Figure 2}

The variable topography and mosaic of land uses found in Centre County, Pennsylvania, taken facing approximately northwest.

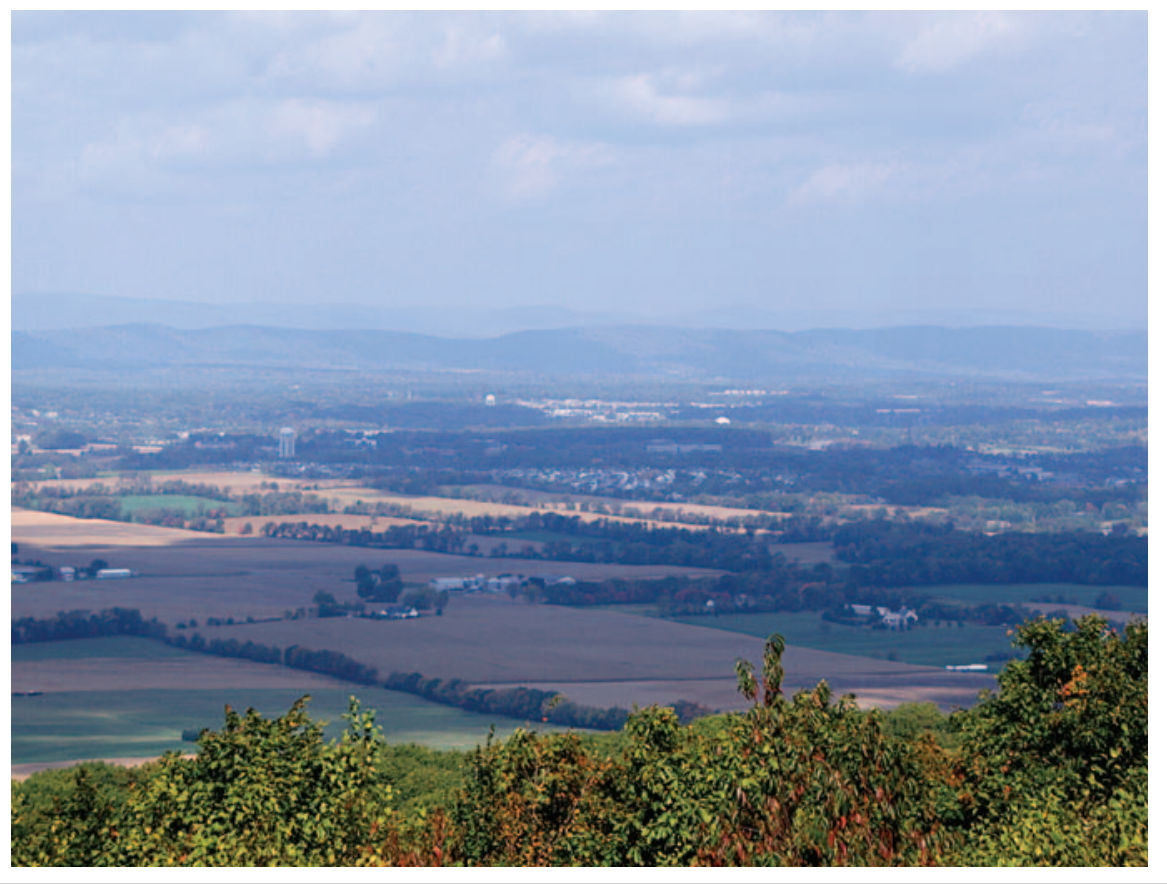

Class 1 , the valley area, comprises $55 \%$ of the county area, but contains nearly all of the agricultural areas and about two-thirds of the developed land (table 1).

Membership probabilities for each pixel were calculated as the percentage similarity between the multivariate centroid of that class and the topo-climatic values for that pixel. In the crisp classification, a pixel belongs to a group if its membership probability is higher for that group than for any other group, regardless of the magnitude of that probability. Figure $3 \mathrm{~b}$ maps the membership probabilities for class 1 and class 2 . The areas of highest membership probability match the crisp classification reasonably well, but figure $3 \mathrm{c}$ highlights an important point: most of the area of the county is at least 90\% similar to either group. Classification variables were standardized to Pennsylvania ranges, and this shows that within the broader statewide context, these two groups are not very different from each other. Some small areas of the county were less than $90 \%$ similar to

\section{Table 1}

Land use in Centre County, Pennsylvania, by class, as percentage of area in that class.

\begin{tabular}{llllll}
\hline Class & Developed & Forest & Pasture & Row crops & Other \\
\hline Class 1 (valley) & 10.9 & 60.7 & 11.7 & 15.6 & 1.1 \\
Class 2 (ridge) & 4.1 & 94.5 & 0.7 & 0.2 & 0.9
\end{tabular}

here was based only on simple topographic and climatic data, probably not the variables that are the most important filters on potential plant communities. This classification work is part of a larger research initiative involving species distribution modeling for forage species and modeling of pasture production; the chosen variables will be those that are important for all three components. The integration of modeling and classification strategies will improve the consistency and objectivity of the classification system, a problem recently identified with rangeland ESDs (Twidwell et al. 2013).

Purely methodological issues also present substantial challenges. The various geospatial datasets required are available at different scales and, sometimes, for different time periods. Determining the most appropriate spatial resolution will be a key component of this analysis: the trade-off between pixel size and computer processing ability is important in a multistate or national project. Data are available at different scales (e.g., 10 $\mathrm{m}$ [33 ft] for gSSURGO, 10 or $30 \mathrm{~m}$ [33 or $98 \mathrm{ft}$ ] for US Geological Survey elevation data, but 800 [2,625 ft] to $4 \mathrm{~km}$ [2.5 mi] for many climate products); merging these products will be an important component of determining the proper spatial resolution. Our ultimate goal is to extend an ecologically based pastureland classification over the entire United States, which will require substantial computer resources and development of techniques to perform complex multivariate analyses with very large datasets.

\section{SUMMARY AND RECOMMENDATIONS}

A hierarchical fuzzy classification framework for agricultural landscapes can incorporate site-specific variation while retaining the usefulness of a traditional landscape classification. Classifications of sites based on topographic, edaphic, and climatic variables selected for their importance to the ecological processes that delimit potential plant communities can provide a management framework for regional and site applications by circumscribing the potential range of land uses and management options at both scales. State and transition models formalize those potential uses and the drivers that can shift a site from one to another, and expert knowledge provides the agricultural context. The combination of multivariate 


\section{Figure 3}

Crisp and fuzzy classifications of Centre County, Pennsylvania, into two groups based on topographic and climatic variables. The solid lines show the boundary between Major Land Resource Areas 127 and 147. Membership probabilities are calculated as percentage similarity between multivariate group centroids and each individual mapped pixel. (a) Crisp classification into two groups, Class 1 (blue) and Class 2 (orange). (b) Membership probabilities for Class 1 (left) and Class 2 (right). (c) Membership probabilities cut at 0.90 . (d) Areas below 0.90 membership probability for both groups.

(a)

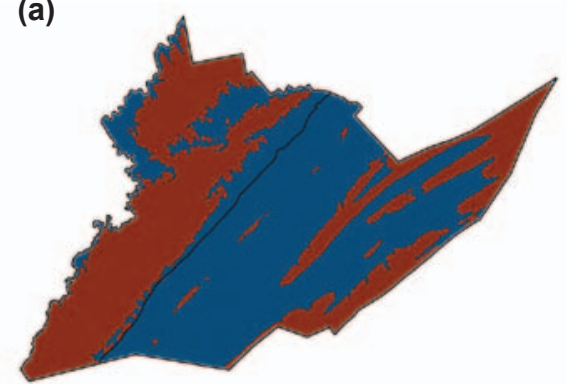

(b)

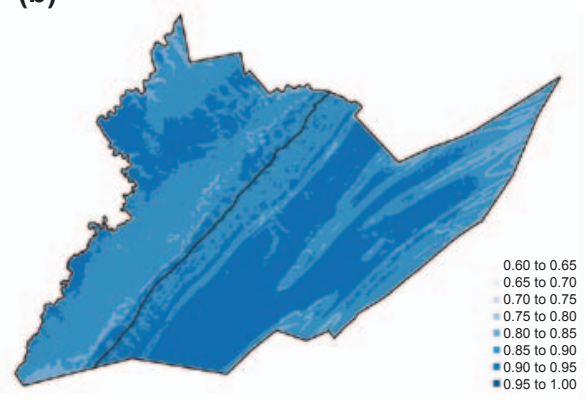

(c)
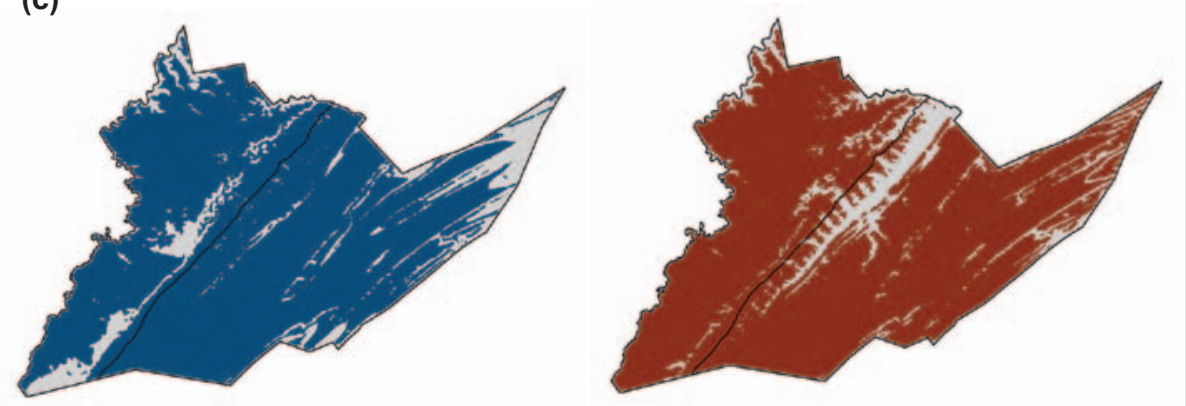

(d)

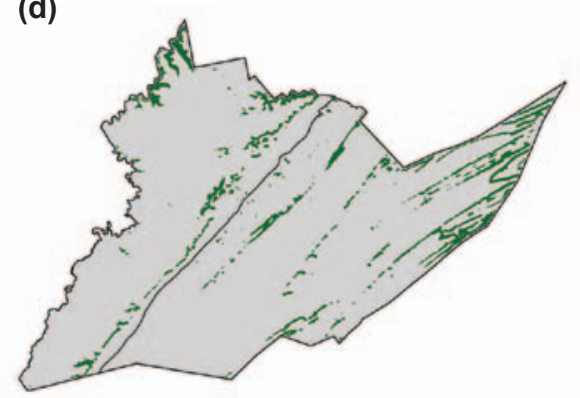

analysis to simplify complex quantitative data and expert knowledge to facilitate interpretation is a powerful approach to understanding agricultural landscapes. This grazed landscape grouping system will serve as the basis for national modeling and monitoring efforts.

\section{REFERENCES}

Bestelmeyer, B.T., J.R. Brown, K.M. Havstad, R. Alexander, G. Chavez, and J.E. Herrick. 2003. Development and use of state-and-transition models for rangelands. Journal of Range Management 56:114-126.

Burrough, P.A., J.P. Wilson, P.F. van Gaans, and A. Hansen. 2001. Fuzzy k-means classification of topo-climatic data as an aid to forest mapping in the Greater Yellowstone Area, USA. Landscape Ecology 16:523-546.

Fry, J., G. Xian, S. Jin, J. Dewitz, C. Homer, L. Yang, C. Barnes,N.Herold, and J.Wickham.2011.Completion of the 2006 National Land Cover Database for the conterminous United States. Photogrammetric Engineering and Remote Sensing 77(9):858-864.

Goslee, S.C., and M.A. Sanderson. 2010. Landscape context and plant community composition in grazed agricultural systems of the northeastern United States. Landscape Ecology 25:1029-1039.

Herrick, J.E., B.T. Bestelmeyer, S. Archer, A.J. Tugel, and J.R. Brown. 2006. An integrated framework for science-based arid land management. Journal of Arid Environments 65:319-335.

Mora, F., and L. Iverson. 2002. A spatially constrained ecological classification: Rationale, methodology and implementation. Plant Ecology 158:153-169.

Nelson, C.J. 2012. Synthesis and perspectives. In Conservation Outcomes from Pastureland and Hayland Practices: Assessment, Recommendations, and Knowledge Gaps, ed. C.J. Nelson, 315-334. Lawrence, KS: Allen Press.

NACSE (Northwest Alliance for Computational Science and Engineering). 2013. PRISM Climate Data. Corvallis, OR: Oregon State University, http://prism.oregonstate.edu.

Rocchini, D., and C. Ricotta. 2007. Are landscapes as crisp as we may think? Ecological Modelling 204:535-539.

Sanderson, M.A.,A. Franzluebbers, S. Goslee, J. Kiniry, L. Owens, K. Spaeth, J. Steiner, and T.Veith. 2011. Pastureland Conservation Effects Assessment Project: Status and expected outcomes. Journal of Soil and Water Conservation 66(5):148A-153A, doi:10.2489/jswc.66.5.148A.

Serra, J.M., J. Cristobal, and M. Ninyerola. 2011. A classification procedure for mapping topo-climatic conditions for strategic vegetation planning. Environmental Modeling and Assessment 16:77-89.

Twidwell, D., B.W. Allred, and S.D. Fuhlendorf. 2013. National-scale assessment of ecological content in the world's largest land management framework. Ecosphere 4(8):Article 94.

USDA NRCS (Natural Resources Conservation Service). 2003. National Range and Pasture Handbook Revision 1. Grazing Lands Technology Institute.

Westoby, M., B.H. Walker, and I. Noy-Meir. 1989. Opportunistic management for rangelands not at equilibrium. Journal of Range Management 42:266-274 